\title{
Life Cycle Assessment (LCA) used to compare two different methods of ripe table olive processing
}

\author{
By Carlo Russo ${ }^{a}$, Giulio Mario Cappelletti ${ }^{\text {* }}$, and Giuseppe Martino Nicoletti ${ }^{\mathrm{a}}$
}

\author{
${ }^{a}$ Dipartimento di Scienze Economico-Aziendali, Giuridiche, Merceologiche \\ e Geografiche (SEAGMeG) - Università degli Studi di Foggia, Via Caggese, 1; 71100 Foggia (Italy),
}

( ${ }^{\star}$ Corresponding author: g.cappelletti@unifg.it)

\section{RESUMEN}

Aplicación de la metodologia Life Cycle Assessment (LCA) entre los diferentes métodos de tratamiento de las aceitunas negras de mesa.

El objetivo de este estudio es analizar el método más común utilizado para el procesamiento de la aceituna negra de mesa "estilo California" (Californian Style). La metodología LCA se aplicó para detectar los puntos calientes del sistema estudiado. Los resultados LCA también nos permitieron comparar el estilo californiano tradicional, aquí llamado "método A", con otro estilo californiano, llamado "método B". Nosotros estábamos interesados en el segundo método, porque la Unión Europea está considerando introducirlo en la Denominación de Origen Protegida (DOP) "La Bella della Daunia".

También fue posible comparar los impactos medioambientales de los dos mètodos californianos con los impactos del método español.

Observando la comparación, está claro que el "método B" tiene un mejor impacto ambiental que el "método A" porque este último requiere más cantidad de agua y electricidad, por lo que el "Estilo Español" para procesar nos da un mejor procesamiento desde el punto de vista ambiental que los métodos del "Estilo Californiano".

PALABRAS CLAVE: Aceituna negra de mesa - Estilo California - LCA.

\section{SUMMARY}

Life Cycle Assessment (LCA) used to compare two different methods of ripe table olive processing.

The aim of the present study is to analyze the most common method used for processing ripe table olives: the "California style". Life Cycle Assessment (LCA) was applied to detect the "hot spots" of the system under examination. The LCA results also allowed us to compare the traditional "California style", here called "method A", with another "California style", here called "method B". We were interested in this latter method, because the European Union is considering introducing it into the product specification of the Protected Denomination of Origin (PDO) "La Bella della Daunia".

It was also possible to compare the environmental impacts of the two "California style" methods with those of the "Spanish style" method.

From the comparison it is clear that "method B" has a greater environmental impact than "method A" because greater amounts of water and electricity are required, whereas
"Spanish style" processing has a lower environmental impact than the "California style" methods. olive.

KEY-WORDS: Black ripe table olives - LCA - Ripe table

\section{INTRODUCTION}

This study continues the environmental analysis of the production chain of table olives. An earlier life cycle analysis emphasized the environmental effects of the cultivation and processing of green Spanish style table olives. The results consistently showed the impact of the plant-protection products used for growing the olives, and of the greenhousegas emissions which result from the pasteurization phase.

Life cycle assessment (LCA) is commonly used for evaluating the environmental performance of products (Acurex, 1993; Baumann et al., 2004; Frischknecht et al., 2007; Guinée et al., 2002; ISO 14040; ISO 14044; Russell et al., 2005; Udo De Haes, 2006), and recently many LCA studies have focused on the agro-food sector (Vigon et al., 2003). A previous life cycle analysis detected the hot spots in the life cycle of table olives, with particular reference to "Spanish style" green table olives (Nicoletti et al., 2007). Depending on when the olives are picked, olive-cultivation produces different types of fruit: the less mature green olives and the riper black olives. The ripe olives are generally processed in the "California style", but the current industrial policy is to pick them while they are still green. The process then consists in darkening them. This method is similar to the "Spanish style" used for processing green olives, but differs in the following ways:

- a greater quantity of water is used;

- compressed air is used to oxidize the drupes;

- ferrous salt is added for fixing the color (Garrido Fernández, 1997).

Like the "Spanish style" method, "California style" processing raises critical environmental issues with regard to the disposal of wastewater, which it produces in even greater quantities. Laboratory tests 
have shown the consistent polluting charge of the lyes, brines and washing waters (Beltran-Heredia et al., 2000a; Beltrán-Heredia et al., 2000b; Beltrán et al., 2001; Brenes Balbuena et al., 1989; Brenes et al., 2000; Fernández et al., 1992; García et al., 1990; Garrido et al., 1992; Garrido Fernández, 1983; Kopsidas, 1994; Rivas et al., 2000; Rivas et al., 2001; Russo et al., 2009, Sánchez Gómez et al., 2006; Vega et al., 1982).

The subject of this study is the production chain of ripe olives, the aim being to assess the amount of pollution caused by the table olive sector. In this case study the analysis focuses on the processing of the raw materials, and compares two variants of the "California style", which we call "method A" and "method B" with reference to the product specification of "La Bella della Daunia" PDO (www.politicheagricole.it).

We avoided analyzing the agricultural and packaging phases, because it can be assumed that the results would be the same as those obtained with the LCA of "Spanish style" green table olives (Cappelletti et al., 2007).

\section{MATERIALS AND METHODS}

\subsection{Goal and scope definition}

LCA methodology was applied to the life cycle of "California ripe table olives" as regulated by ISO 14040 and ISO 14044 standards. Taking a cue from a proposal made by the olive-producers' association to introduce another process ("method B"), both "methods A" and "B" were examined (Cappelletti, 2008). Figure 1 shows the inputs and outputs of energy and resources for the two methods used by the production industries. As for the inventory analysis, all the energy and material flows refer to the functional unit represented by $100 \mathrm{~kg}$ of picked olives. The CML 2001 method was used for impact assessment, and the damage categories considered were: abiotic depletion potential $(A D P)$, acidification potential $(A P)$, eutrophization potential (EP), freshwater aquatic ecotoxicity potential (FAETP inf.), global warming potential (GWP 100 years), human toxicity potential (HTP), marine aquatic ecotoxicity potential (MAETP),

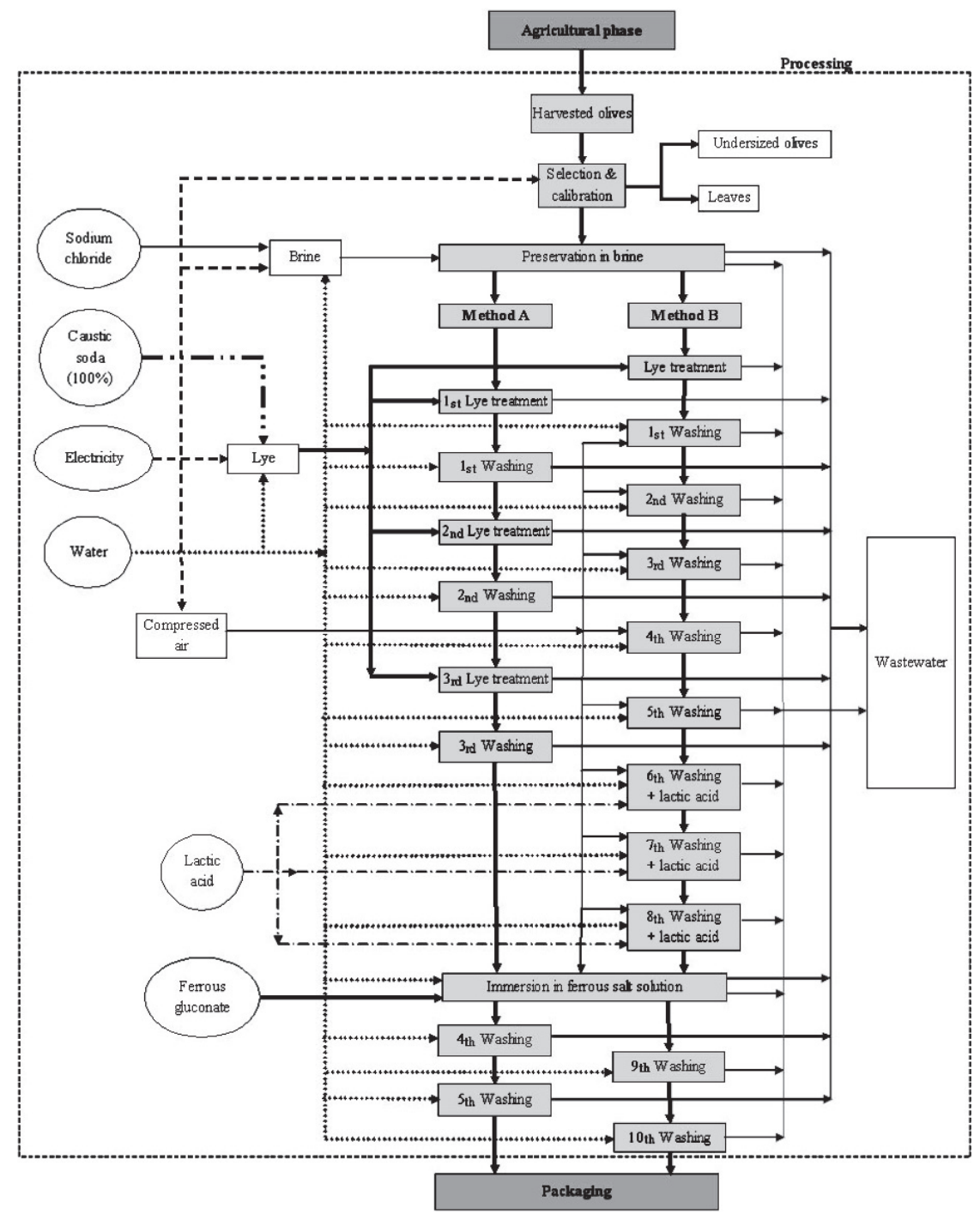

Figure 1

Layout of the "California process", "methods A" and "B". 
ozone layer depletion potential (ODP, steady state), photochemical ozone creation potential (POCP), terrestric ecotoxicity potential (TETP) and energy use (EU).

\subsection{Inventory Analysis (LCl)}

"Methods A" and "B" of "California style" processing were singled out for examination. Each percentage value refers to the quantity of water (65 $\mathrm{kg}$ for $100 \mathrm{~kg}$ of cleaned olives). After the stages of selection, calibration and preserving in brine at 10 $\% \mathrm{NaCl}$ (all of which are common to both methods) we considered three lye treatments for "method A" (the first with a solution of $2 \% \mathrm{NaOH}$, and the other two with a lye of $0.5 \% \mathrm{NaOH}$ ) and five washes with water, one with ferrous gluconate added to fix the black color. During all the washes compressed air is injected into the water to speed up the oxidation of the olives. "Method B", on the other hand, makes use of only one debittering process (with a lye of $2 \% \mathrm{NaOH}$ ) and more washes (eleven in all):

- the first five using only water;

- the next three with the addition of lactic acid (about 0.3\%);

- one treatment with water and ferrous gluconate to fix the black color;

- two washes, at the end, to remove the residue of ferrous salts and have a finished product which is ready for packaging.

As with "method A", here too compressed air is injected into the water during each wash, to promote oxidation of the drupes and help to fix the black color.

\section{Data quality}

The data was collected from local processing industries. The electricity consumption and other input quantities were measured directly. We assessed waste-water pollution by means of laboratory analysis. All these calculations were made using GaBi4 software and Ecoinvent Databases (IKP and PE, 2002.).

\section{RESULTS AND DISCUSSION}

Table 1 set out an initial comparison between the two methods during the inventory phase, highlighting the input quantities for black olive processing. "Method B" requires larger quantities of all inputs, with the exception of caustic soda which is only twothirds of that used for "method A".

\subsection{Life Cycle Impact Assessment (LCIA)}

Figures 2.a and 2.b show the normalized impacts of the two California style processing methods, taking into consideration only those categories of damage (EP, GWP and MAETP) that have shown significant values. The two methods show the same
Table 1

Energy and resources input of the two "Californian style" variants, with reference to $100 \mathrm{~kg}$ of raw material

\begin{tabular}{lccc}
\hline \multicolumn{1}{c}{ Input } & & Method A & Method B \\
\hline Water & $\mathrm{kg}$ & 585.06 & 780.06 \\
Electricity & $\mathrm{kWh}$ & 20.2 & 27.26 \\
Sodium chloride & $\mathrm{kg}$ & 9.42 & 9.42 \\
Caustic soda (100\%) & $\mathrm{kg}$ & 1.96 & 1.30 \\
Ferrous gluconate & $\mathrm{kg}$ & 0.25 & 1.25 \\
Lactic acid & $\mathrm{kg}$ & 0.20 & 0.59 \\
\hline
\end{tabular}

environmental hot spots, with the impact categories EP and MAETP being noticeably affected by the polluting charge of the wastewater deriving from the phase of preservation in brine, from the washes and from the phase of immersion in a ferrous salt solution.

Figures 3, 45 and 6 show the environmental impacts caused by the different phases of the two processing methods, with reference to the functional unit which is divided into sub-phases. For the categories of impact EP, GWP, MAETP, EU the higher number of washes of "method B" caused a greater environmental impact compared to "method A", while the lower number of lye treatments caused minimal environmental improvements.

The next stage of the analysis was to compare the environmental effects of the two methods, so as

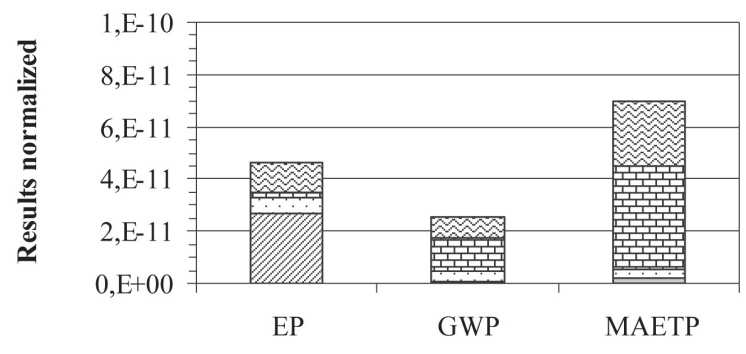

$\square$ Selection \& calibration $\quad \square$ Preservation in brine

$\square$ Lye treatment 四 Immersion in ferrous salt solution จ Washes

2.a Method A.- Results normalized

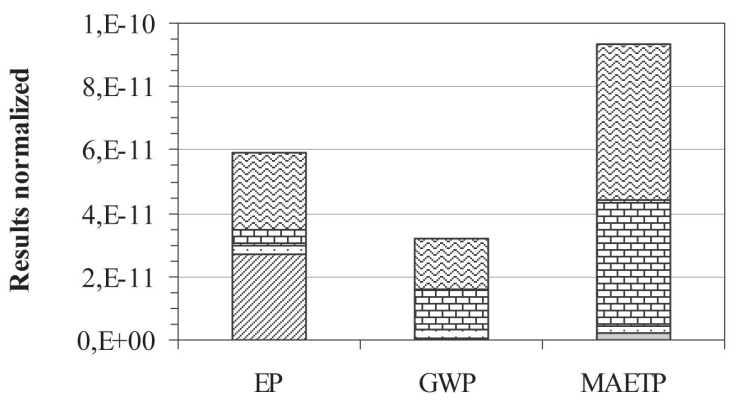

$\square$ Selection \& calibration $\quad \forall$ Preservation in brine

$\square$ Lye treatment

臣 Immersion in ferrous salt solution

Washes

2.b Method B.- Results normalized

Figure 2

The environmental impacts of the "Californian style" process. 


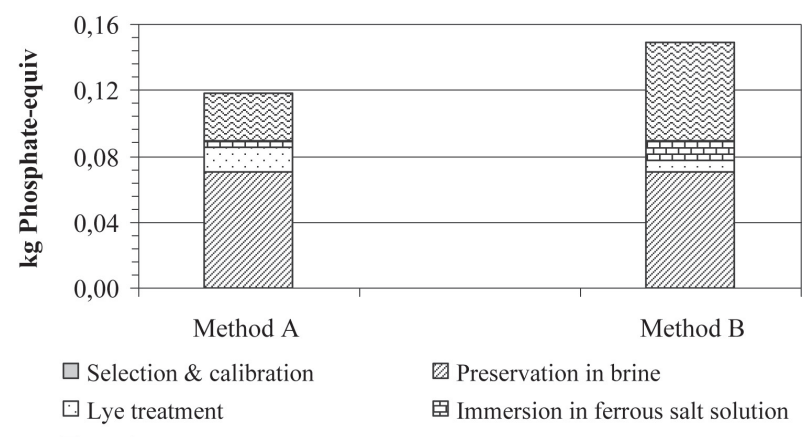

Figure 3

Eutrophization Potential (EP) by the different phases of the two processing methods.

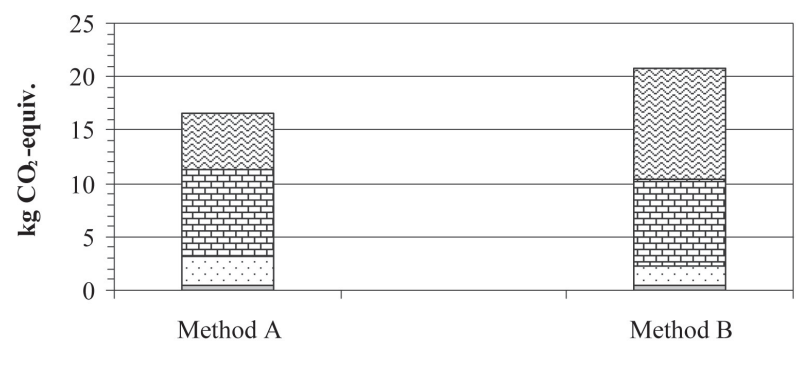

$\square$ Selection \& calibration $\square$ Lye treatment

Washes

$\square$ Preservation in brine

⿷ Immersion in ferrous salt solution

Figure 4

Global Warming Potential (GWP) by the different phases of the two processing methods.

to determine the effect of using different amounts of energy and resources (figure 7). For the same quantity of olives processed, "method B" consumes more electricity (because it uses air-compressors and pumps for filling and draining the containers during the many washes); moreover the quantity of water used is almost double that used for "method A". As a result "method B" has a greater polluting impact than "method A", since all the damage categories examined clearly show higher values for this method, with the exception of ODP (which is higher in "method A" because of the larger quantity of caustic soda used in that method).

\subsection{Improvement hypothesis}

The LCA analysis of the "California style" method enabled us to conclude that the critical environmental impacts of the two variants, "methods A" and "B", are more or less the same. Among the hot spots detected, the consumption of energy for injecting compressed air into the water during all the washes -and especially during the color-fixing phase (common to both methods)- is without doubt the one that merits particular attention. Oxidizing the drupes to fix the black color is a fundamental stage of both processes. With reference to the product specification of "La Bella della Daunia" PDO, the black color is an important characteristic when selling this type of table olive. From an environmental point of view, the process could be improved by following two strategies: a) minimizing the impacts deriving from energy production by, e.g., installing renewable energy sources at the processing plants; b) improving the technology aimed at reducing electricity consumption by, e.g., placing the olives in the open air to oxidize.

The comparison between the impacts of the two different "California style" methods demonstrates that the environmental benefits resulting from using less caustic soda in "method B" are overruled by the effects of the numerous washes; this is due to the weaker $\mathrm{NaOH}$ concentration of the alkaline solution. Changing from "method A" to "method B" results in greater environmental impact due to a higher consumption of resources and energy and larger quantities of wastewater which then has to be disposed of. We should also take into consideration the fact that the adoption of the new variant of the "California style" (and the resulting proposal to modify the product specification of "La Bella della Daunia" PDO) does not stem from an environmental requirement, but rather from economic pressure to obtain a product with better chemical-physical and organoleptic characteristics.

The choice between the two methods will probably be determined by finding out which finished product appeals more to consumers and also gives the producers economic advantages.

\subsection{Comparison between "California style" and "Spanish style"}

As we wanted to give a complete picture of the environmental performance of the most common industrial methods used for producing table olives, we continued our analysis by comparing the results of an earlier LCA of "Spanish style" olives (Nicoletti et al., 2007) with those of "Californian style" processing, "method A" (which is less polluting than "method B").

After comparing these two processes, it is clear that the production of green olives is less polluting than that of black olives. The consumption of electricity and resources are undoubtedly lower with "Spanish style" olives than with "Californian style" olives produced using "method A".

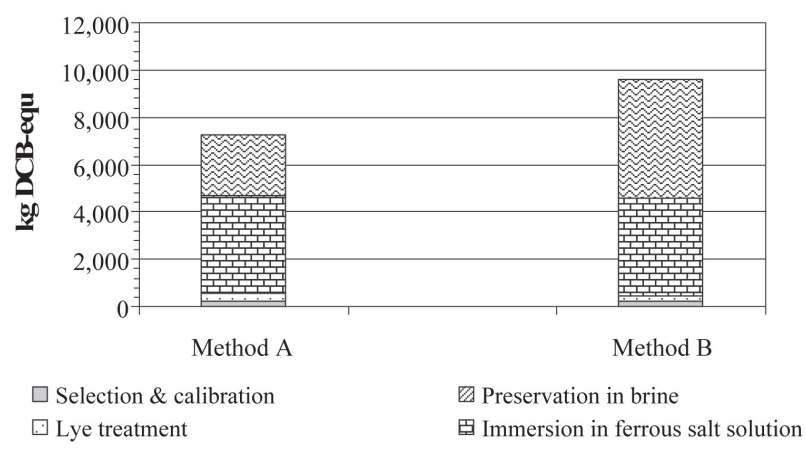

Figure 5

$\checkmark$ Lye treatment

圆 Washes

Marine Aquatic Ecotoxicity Potential (MAETP) by the different phases of the two processing methods. 


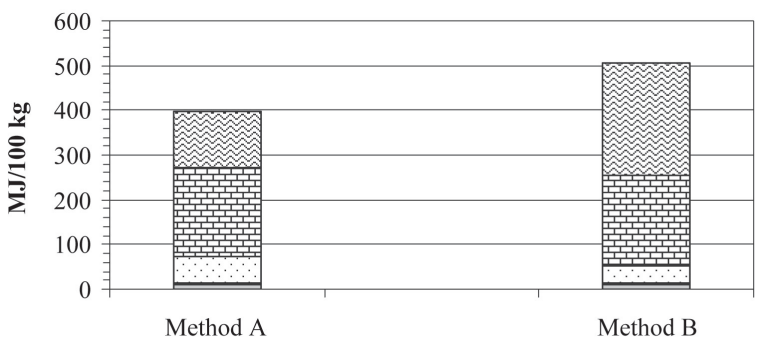

$\square$ Selection \& calibration $\square$ Lye treatment 国ashes

Preservation in brine

E Immersion in ferrous salt solution

Figure 6

Energy Use (EU) by the different phases of the two processing methods.

Figure 8 highlights the differences between the two processes, with regard to each impact category. By setting the "Spanish style" effects to a score of 100 , it can be seen that the scores for "Californian style method A" are about 16 times higher for MAETP, 9 times higher for GWP and around 20 times higher for EU. It is rather interesting that the scores for EP are very similar for both processes: this demonstrates that the environmental problem deriving from the wastewater is a critical point in common and, above all, that the impact of the EP is not proportional to the quantity of wastewater produced. The amount of wastewater produced by "Spanish style" processing is considerably less than that produced by the "Californian style" method. However, as can be seen in figure 4, the EP contribution is almost the same.

The consequences of the larger amount of $\mathrm{NaOH}$ used in "Californian style" processing are evident in the impact category ODP, which shows a higher percentage value for this method. However the other categories (ADP, AP, FAETP, HTP, POCP and TETP) follow the general trend of the results.

Based on this comparison, we can affirm that "Californian style method A" processing is more detrimental to the environment than "Spanish style" processing.

\section{CONCLUSION}

In this study we used LCA methodology to analyse two variants of "Californian style" olive processing (here called "methods A" and "B") which both produce ripe table olives. We were able to detect the "hot spots" of the process, and we also compared the two methods with the "Spanish style" method used for processing green olives. After studying the results of the LCA of the "Californian method", we are able to affirm that the smaller quantity of caustic soda used in "method B" does not result in environmental benefits but, rather, adds to the overall impact because greater amounts of water and electricity are required.
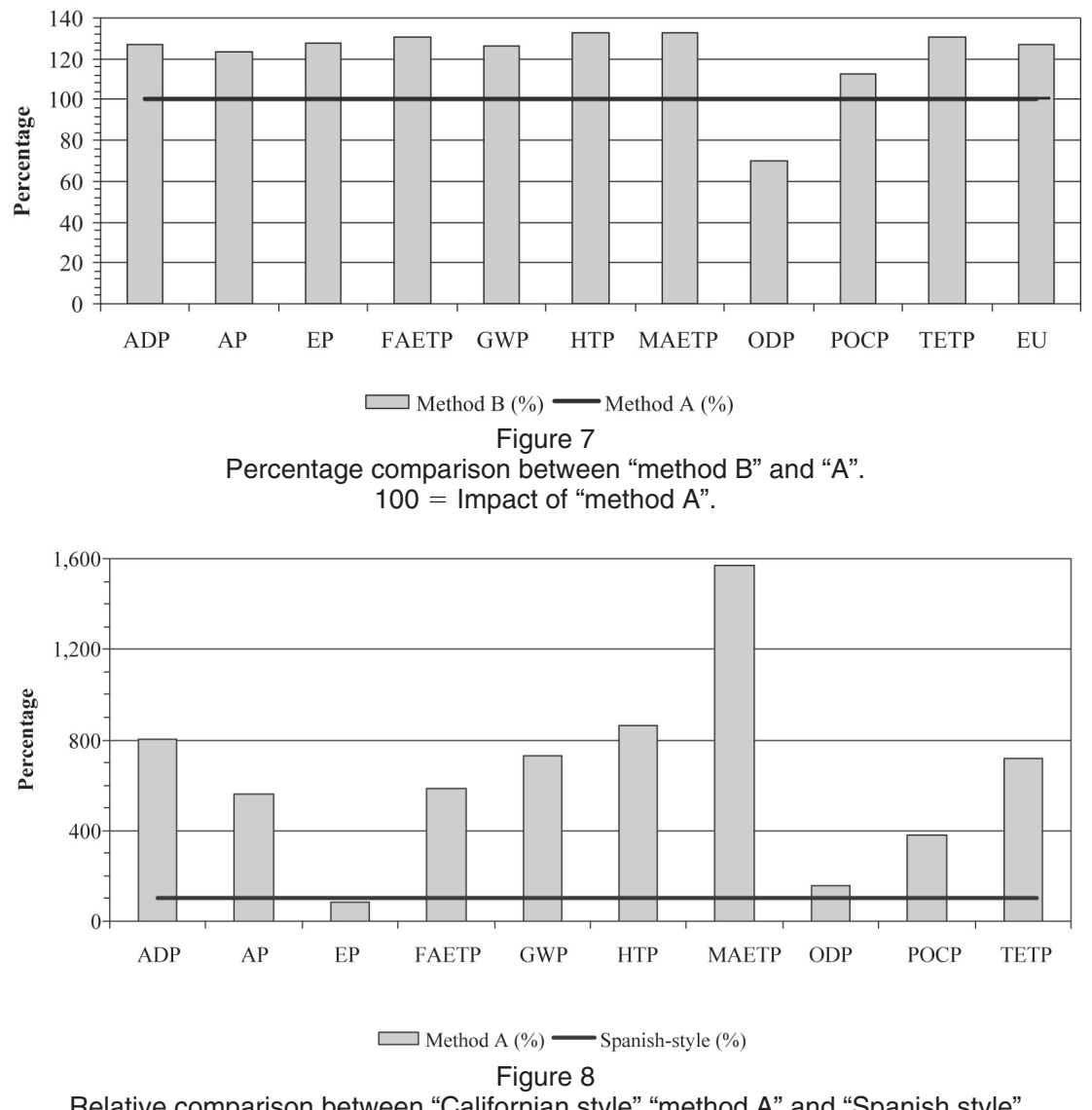

Relative comparison between "Californian style" "method A" and "Spanish style" (100 = impact of the "Spanish style" process). 
From the comparison it is clear that "method B" has a greater environmental impact. However, as it gives a better quality end product, it will probably continue to be the method more frequently used by the industry. In consideration of these facts, there has been a proposal to combine "methods A" and "B" in the production of "La Bella della Daunia" PDO.

The study concludes by comparing its results with those presented in an earlier LCA of green "Spanish style" olives (Nicoletti et al., 2007). Even though the processes compared make use of different technologies to obtain end products each with distinct organoleptic characteristics, we can state that "Spanish style" processing gives a better environmental performance than the "Californian style" methods. "Method B" of the "Californian style" processing appears to be the most polluting overall, due in particular to its high electricity consumption. This comparison also enables us to point out a common negative aspect with regard to the EP and emphasizes how important it is to find a solution to this problem, such as reusing the lyes and brines or recovering useful substances from the wastewater. This would reduce the pollution but would also, at the same time, be economically advantageous for the producers.

Finally it should be noted that problems are only to be expected, when the results of environmental analyses are in conflict with economic interests. Business management usually gives priority to choices based on financial motives, and does not often take sustainability factors into consideration. This is particularly the case in areas such as the one examined in this study, and so our aim should be to convince the industry to be aware of environmental problems and objectives. This would reinforce the relationship between the producers, any other interested parties and the geographical area where the raw material is cultivated and processed.

\section{CONTRIBUTION OF AUTHORS}

This paper has been thought, discussed and written by three authors and it is the result of their common commitment in particular: C. Russo contributed to data collection and classification, and bibliographical research, G.M. Cappelletti, contributed to elaboration and comment on data, G.M. Nicoletti contributed to planning and final review of research.

\section{REFERENCES}

Acurex Environmental Corporation, Aul E. \& Associates Inc., Pechan E. H. \& Associates Inc. 1993. Emission factor documentation for AP-42 section 1.5 Liquefied Petroleum Gas Combustion. Supplement B, October 1996. U. S. Environmental Protection Agency, Research Triangle Park, NC, U.S.A.

Baumann H, Tillman AM. 2004. The Hitch Hiker's Guide to LCA. Studentlitteratur, Lund, Sweden.
Beltrán-Heredia J, Torregrosa J, Dominguez JR et al. 2000a. Aerobic biological treatment of black table olive washing wastewaters: effect of an ozonation stage. Process Biochemistry 35, 1183-1190.

Beltrán-Heredia J, Torregrosa J, Dominguez JR. et al. 2000b. Ozonation of black-table-olive industrial wastewaters: effect of an aerobic biological pretreatment. Journal of Chemical Technology and Biotechnology 75, 561-568.

Beltrán F, García-Araya JF, Navarrete V, Gimeno O. 2001. Treatment of wastewater from table olive industries: quantum yield of photolytic processes. Bulletin of Environmental Contamination And Toxicology 67, 195-201.

Brenes Balbuena M, De Vicente Fernández J, García García P, Garrido Fernández A. 1989. Characteristics of waste waters from the elaboration of table olives. Grasas y Aceites 40, 287-290.

Brenes M, García P, Romero C, Garrido A. 2000. Treatment of green table olive waste waters by an activated-sludge process. Journal of Chemical Technology and Biotechnology 75, 459-463.

Cappelletti GM, Nicoletti GM, Russo C. 2007. Analisi comparata dei vari sistemi di packaging nel settore delle olive da mensa, mediante l'utilizzo dell'LCA. Atti del XXIII Congresso Nazionale di Merceologia, Vol. I, 172-177, Terracina (Italy), 26-28 September 2007.

Cappelletti GM. 2008. La tutela della tipicità per le olive da mensa. Industria Conserve 83, 45-52.

Fernández AG, Balbuena MB, García PG. 1992. Treatment for green table olive fermentation brines. Grasas y Aceites 43, 291-298.

Frischknecht, R, Jungbluth N, (Editors) 2007. Overview and Methodology - Ecoinvent report No. 1. Dübendorf, December 2007 from

http://www.ecoinvent.org/fileadmin/documents/en/01_ OverviewAndMethodology.pdf

García PG, Balbuena MB, Fernández JD et al. 1990. Physicochemical depuration of the waste-waters from the green table olive packing industries. Grasas $y$ Aceites 41, 263-269.

Garrido Fernández A. 1983. Study of ripe olive wastewaters and their reusing possibilities. Grasas $y$ Aceites 34, 317-322.

Garrido A, García P, Brenes M. 1992. The recycling of table olive brine using ultrafiltration and activated carbon adsorption. Journal of Food Engineering 17, 291-305.

Garrido Fernández A, Fernández Diez MJ, Adams MR. 1997. Table Olives, Chapman \& Hall, London, UK.

Guinée JB, Gorée M, Heijungs R, Huppes G, Kleijn R, de Koning $A$, van Oers $L$, Wegener Sleeswijk A, Suh S, Udo de Haes HA, de Bruijn $\mathrm{H}$, van Duin R, Huijbregts MAJ. 2002. Handbook on life cycle assessment - Operational guide to the ISO standards. Kluwer Academic, Dordrecht Publishers, Dordrecht. Retrieved from http://www.leidenuniv.nl/cml/ssp/projelKP and PE 2002. GaBi 4 - Software-system and databases for life cycle engineering. Stuttgart. Echterdingen (www.gabisoftware.com).

ISO 14040 2006. Environmental management - Life cycle assessment - Principles and framework (ISO 14040:2006). International Standard of Organization (ISO), Geneva, Switzerland.

ISO 14044 2006. Environmental management - Life cycle assessment - Requirements and guidelines (ISO 14044:2006). International Standard of Organization (ISO), Geneva, Switzerland. 
Kopsidas GC. 1994. Waste-water from the table-olive industry. Water Research 28, 201-205.

Mattson B, Sonesson U. (Editors) 2003. Environmentally - Friendly Food Processing. Woodhead Publishing Limited, Cambridge, England.

Nicoletti GM., Cappelletti G. M., Russo C. 2007. LCA of Spanish-style green table olives. $5^{\text {th }}$ International Conference LCA in Foods 2007, Gothenburg, Sweden, 25-26 April 2007.

Rivas FJ, Beltrán FJ, Gimeno O. 2000. Joint treatment of wastewater from table olive processing and urban wastewater. Integrated ozonation-aerobic oxidation. Chemical Engineering \& Technology 23, 177-181.

Rivas FJ, Beltrán FJ, Gimeno O et. al. 2001. Chemicalbiological treatment of table olive manufacturing wastewater. Journal of Environmental EngineeringAsce. 127, 611-619.

Russell A, Ekvall T, Baumann H. 2005. Life cycle assessment - introduction and overview. Journal of Cleaner Production 13, 1207-1210. Retrieved from http://www.sciencedirect.com/science/article/B6VFX4GDBT7K-3/2/f65de94ab5f9d393a731395c5a2 6 be18.

Russo C, Cappelletti GM, Nicoletti GM. 2009. LCA of Californian black-ripe table olives. Proceedings of the 6th International Conference on LCA in the AgriFood Sector - Towards a sustainable management of the Food chain. November 12-14, 2008, Zurich, Switzerland, Nemecek, T. \& Gaillard, G. (eds.), Agroscope Reckenholz-Tänikon Research Station ART, June 2009.

Sánchez Gómez AH, García García P, Navarro LR 2006. Elaboration of table olives. Grasas y Aceites, 57, 86-94.

Udo De Haes HA. 2006. Sustainable management of natural resources in all Life-cycle perspective. International Journal of Life Cycle Assessment 11, 2. Retrieved from http://dx.doi.org/10.1065/lca2006.01.001.

Vega MN, Ladrón RV, Ramos RD. 1982. Utilization possibilities of by-products from table olive industry. Grasas y Aceites 33, 135-139.

www.politicheagricole.it/NR/rdonlyres/ectopttj6xg4qud26 jfdvppuzpjhm3cyk2mulbjwym57gfwvx7ni6kngej2tr2d 42yql2Iwcjic5rxmmtuzql37zgnh/20081117_ Disciplinare esameUE Bella Daunia_DOP modifica.pdf

Recibido: 4/8/09 Aceptado: 23/9/09 